\title{
Communication Strategy of Zhaojun Culture in Xingshan County Under the Background of Rural Revitalization
}

\author{
Xiaodong Lei ${ }^{1, \text { a }}$, Yunpu Chen ${ }^{2, \mathrm{~b}}$, Xin Yang ${ }^{3, \mathrm{c}}$ \\ ${ }^{I}$ Teaching Assistant, School of Literature and Media, China Three Gorges University \\ ${ }^{2}$ Professor, School of Marxism, China Three Gorges University \\ ${ }^{3}$ Undergraduate Student, School of Literature and Media, China Three Gorges University \\ aNini5957@139.com \\ ${ }^{b}$ cyplyzcz@sina.com \\ c2861752517@qq.com
}

\begin{abstract}
Since the rural revitalization strategy was proposed, adjusting and optimizing the rural industrial structure and vigorously developing the rural cultural industry have become the focus of rural development. The Xingshan County in Yichang City, with a pleasant environment surrounded by mountains and renowned for Zhaojun culture, continuously enriches cultural resources, develops cultural industries to seek new growth, and finally achieves poverty alleviation. As the hometown of Zhaojun, one of the Four Beauties of ancient China, it boasts a profound cultural heritage. The county is committed to spreading Zhaojun culture with the integration of intangible cultural heritage and actively innovating and advancing with the times in the communication practice, which provides a practical and helpful reference for other places to realize beautiful rural poverty alleviation.
\end{abstract}

Keywords: Rural Revitalization, Zhaojun Culture, Communication Strategy

\section{INTRODUCTION}

The rural revitalization strategy has injected strong vitality into the rural development in China, establishing itself as a powerful policy guarantee for realizing and guiding rural economic transformation and promoting the rapid development of rural areas. China's long history has created many spiritual and cultural labels in rural areas. Taking Xingshan County in Yichang City in Hubei Province as an example, Wang Zhaojun, the Messenger of Peace, serves as its representative cultural gene. The cultural image and national spirit represented by Wang Zhaojun have determined the sustainable development path and future of Xingshan County to build beautiful countryside. In recent years, Xingshan County has never stopped exploring the dissemination of Zhaojun culture. Be it the naming of local places, landmarks and streets, or the formation of folk art troupes, "excavating unique stories and recalling the memory of Zhaojun" has been used in various fields of communication practice. From the creation of the regional environment, through the promotion of multiple media, to the establishment of the Zhaojun brand and the inheritance of intangible cultural heritage, the county spares no effort to explore how to protect and inherit the Zhaojun culture while expanding publicity and improving the quality of life and benefits of the people.

\section{COMBINE CULTURE AND MARKET TO STRENGTHEN CHARACTERISTIC PUBLICITY AND RECALL THE MEMORY OF ZHAOJUN}

Xingshan County in Yichang City enjoys beautiful scenery with green mountains and clear waters. It can be seen from the local chronicles, "Xiangxi in Xingshan County is where Wang Zhaojun used to visit, and Xiangxi is named after Zhaojun Village." It is Wang Zhaojun, one of the "Four Great Beauties," that has made this quiet and beautiful mountain village outstanding. The hometown of celebrities serves as an important part of the promotion of celebrity culture. As a cultural resource and unique landmark, "Hometown of 
Zhaojun" is not only the core of rural cultural construction in Xingshan County in Hubei Province and the boosting force for regional development but more a powerful manifestation of the development of the beautiful countryside and the comprehensive realization of poverty alleviation policies and practices in China in the new era.

\subsection{Labeled Publicity}

Within the quiet and beautiful landscape of Xingshan had Wang Zhaojun, the well-known "Zigui First Beauty," growing up. From ancient times to the present, folk legends and stories about Zhaojun's beauty and Zhaojun's marriage to unify nations have been widely circulated, labeling this land as beautiful. "Things are valuable for the reputation while places distinguish with the people." Labeling does not hinder the development of cultural resources and the promotion of celebrities' hometowns, but endows the place with uniqueness. Xingshan County relies on the combination of "the beauty of people" and "the beauty of scenery" to expand regional publicity and maximize the economic and cultural values of environmental beauty, during which the priority falls on creating characteristic scenic spots and preparing for publicity on new media. The beauty in the scenic area should be completed first. Taking "Zhaojun Huansha Square" as an example, designed upon the poem "the voice of Pipa played by the beauty lingers around," this sculpture of the 16-year-old Zhaojun smiles brilliantly, deeply integrating itself with the beauty of the environment. It later becomes a scenic spot for online celebrities to take photos. The next move falls on publicity with real-time announcements on WeChat, Weibo, Douyin and other new media platforms. For example, the official WeChat public account of Xingshan County, "The Harmonious and Beautiful Xingshan," emphasizes the keyword "beauty." The combination of mountains, a river, and beauty constitutes the symbolic aesthetics of Xingshan County, creating a majestic vitality for its development.

\subsection{Personalized Market}

Accurately grasping market trends and determining the audience is the core of creating personalized product marketing. In recent years, "Internet celebrity check-in places" have become one of the marketing directions of tourism products. Scenic spots where high-level and atmospheric photos can be taken tend to be more attractive to young people, by which the Hongyadong in Chongqing is regarded as the "real spirited away," and Anaya Qinhuangda becomes the choice for wedding photoshoots. "The most beautiful water road" and "Flowers under the forest" in Xingshan County in Yichang City are used as propaganda resources to create an intense Zhaojun cultural atmosphere. While the cultural background with Zhaojun characteristics is favored by Han Chinese clothing fans from all over the country, it also attracts experts and scholars to conduct field research, creating a promising market prospect for the local area. The story of peace envoy Wang Zhaojun marrying the Hun is so well-known in China that it makes her an inspiration source and a description object of literary works by literati in the past." What is behind the image of Zhaojun are the true story of Zhaojun's marriage and the everlasting "Zhaojun culture." Nearly a thousand poems reflect Wang Zhaojun's life or integrity, including classic poems written by $\mathrm{Li}$ Bai, $\mathrm{Du} \mathrm{Fu}$, and Wang Anshi. The large-scale oriental poetic stage drama "Zhaojun Departs the Frontier," directed and starred by modern singer, Chinese young performance artist Li Yugang, has been toured worldwide and well received by audiences at home and abroad. The environment and a good market area on which the development of the hometown of celebrities depends are indispensable. Relying on the historical celebrity effect, Xingshan County in Yichang strengthens the connection between celebrities' visits to Zhaojun's hometown, the creation of literary works and Xingshan County. It also relies on the beautiful ecological environment to magnify the beauty of the "The mountain village where Wang Zhaojun grew up still exists today" in the poems, presenting to the public "the hometown of Zhaojun in the impression of literati."

\subsection{Collective Memory}

Because of the uniqueness of celebrity resources, further exploration of Zhaojun's story is a collective memory. Zhaojun's hometown has witnessed Zhaojun's growth path, which not only enables people to trace the material entities - Niangniang well, dressing table, and Full Moon Building, but also delivers a unique feeling of nostalgia. Therefore, Xingshan County is committed to the three-dimensional publicity of Zhaojun's legends and anecdotes, displaying a more authentic and detailed image other than "Zhaojun departs the frontier" and "Four Great Beauties" and cherishing the unique right to speak as Zhaojun's hometown. Thus, only with rigid and commercial publicity is far from enough. Xingshan has created an intense Zhaojun cultural atmosphere in public infrastructure and spared no effort in training the quality of villagers. The local people, regardless of men, women and children, can all tell the tourists a few stories about Zhaojun and recite a few poems about Zhaojun, integrating Zhaojun culture into their blood. Zhaojun culture constitutes an important part of Chinese civilization and also symbolizes a beautiful brand of Xingshan's external exchanges. Xingshan County continues to upgrade the degree of integration between the collective memory of the homeland and Zhaojun culture, incorporate "spirit of harmony and beauty" into the common spiritual connotation, and spread it to all parts of the world. 


\section{COMBINE CULTURE AND MEDIA TO ENRICH COMMUNICATION CARRIERS AND BROADEN COMMUNICATION CHANNELS}

The multi-cultural dissemination necessitates the internal expression of different carriers and the external manifestation of different channels, which complements each other. Only by co-innovating both the communication carrier and the communication channel can the excavation and publicity of cultural resources be upgraded. Against the all-media era, Zhaojun culture in Xingshan County has been spread from print traditional paper media to mobile news apps with official platforms such as WeChat public accounts, Weibo, and Douyin. With the combination of online real-time publicity and offline series of cultural activities and performances, a real-time linkage of "online + offline" is established with both the media and channels of communication advancing with the times and bringing forth new things.

\subsection{Renovation on the Communication Carriers}

The inner spiritual value of the cultural resources of historical celebrities should rely on the outer material entities. The multi-transmission of Zhaojun culture requires the unity of the cultural and economic characteristics of the dissemination carrier. While cultural values have been realized, local economic development must also be promoted. Xingshan County is bound to develop a series of landscapes as the material carrier of Zhaojun, the cultural nature of which can be displayed through the construction of Zhaojun Memorial Hall, sculptures and cultural squares. In addition, tourism products should be created to enrich the material carrier of Zhaojun's hometown tourism to equip the local tourism with "spectacles" and "fun" and boost economic benefits. Integration, of course, is the best plan. And the light and shadow show of "Zhaojun-Dream to Hometown" is such a typical integration product. It not only narrates Zhaojun's "faithful and broad-minded, and courageous beauty" in a modern way, but also allows tourists to participate and interact under the multimedia 4D experience mode. Its interesting nature establishes itself as a hot spot for publicity, attracting more tourists to increase purchasing power and consumption.

\subsection{Integration of New and Old Media}

Against the all-media era, the integration of traditional media and new media is the general trend, which establishes a communication channel for "the integration of the old and the new." This effective integration expands the communication scope of
Zhaojun culture and improves communication efficiency. On February 3, 2021, the China Internet Network Information Center (CN NIC) released the 47th "Statistical Report on China's Internet Development Status" in Beijing. The "Report" shows that as of December 2020, the number of Internet users in China has reached 989 million, with an increase of 85.4 million from March 2020 and a 70.4\% Internet penetration rate 1 . Given the irresistible momentum of new media, cultural publicity can no longer achieve the desired effect only by relying on traditional media, and media integration is the trend of the times. Traditional media attach importance to content, while new media emphasizes interaction. Through the operation model of the "content + technology," the best effect of engaging content and two-way communication can be achieved, so that the audience can have a deep impression in the communication process of related integrated media products. For example, the release of short videos of Zhaojun cultural records to expand the network coverage and the production of interactive, integrated media products in Zhaojun Memorial Hall, can trigger young people's interest in visiting, realize online and offline joint promotion, and increase discussion about the tourist attractions in Xingshan County. Program promotion in mainstream media also stands as a good way. For example, CCTV's large-scale comprehensive program "Remember the Nostalgia" enters Xingshan, spreads Zhaojun culture, and presents the beauty of Xingshan on the screen, enabling more people to know and visit Xingshan, greatly enhancing Xingshan's popularity and reputation.

\section{COMBINE CULTURE AND BRAND TO ESTABLISH THE IMAGE OF ZHAOJUN AND START A CULTURAL BRAND}

To enhance the cultural influence of Zhaojun and drive the innovation of the cultural industry, the establishment of Zhaojun's image and Zhaojun brand stands as an extremely important starting point. To a large extent, branding also means "going out." As the story of Zhaojun enjoys a long history and vivid and complex characters, the creation of a unique cultural brand can be considered from three aspects, namely historical brand, literary brand, and integrated brand. In the process of spreading Zhaojun culture, Xingshan County relies on brand image to vigorously develop the rural cultural industry, which not only adjusts and optimizes the rural industrial structure in China, but also narrows the urban-rural cultural gap and promotes urban-rural integration. Cultural brands, whose existence and development are determined by the acceptance by the public, need to keep pace with the times and adapt to the modern social environment. Only through continuous innovation can Chinese stories be better told and Chinese voices be conveyed. (2) 


\subsection{Based on Historical Brands}

The historical records about Zhaojun's departure from the fortress are not abundant enough. The main sources for obtaining official history depend on "Book of Han" by Ban $\mathrm{Gu}$ and "Book of the Later Han, the Biography of Southern Hun" by Fan Ye. The image of Zhaojun as an ancient woman is doomed to be extraordinary under the destiny of marriage. For future generations, her marriage is a carrier and a symbol of peace, playing a certain historical role in enhancing the trust between Han and Hun and consolidating friendly relations. Therefore, when promoting Zhaojun's image, its historical influence should not be exaggerated deliberately but objectively explain its symbolic significance of "safeguarding national peace" and the historical significance of the messenger of peace.

\subsection{Based on Literary Brands}

The experience of Zhaojun departing the frontier has left posterity with plenty of room for imagination and creation. Various stories of Zhaojun have been derived from the people, and different angles of Zhaojun have been portrayed by the literati. The Wang Zhaojun recorded in "Qin Cao" struggled to defend her personal dignity throughout her life, while the one in "Xijing Miscellaneous" refused to bribe painters and bow to the secular. With the changes of dynasties, people under different social backgrounds have different "Zhaojun" in their hearts. Literati expressed their outlook on life through the shaping of Zhaojun. For example, in Du Fu's "Five Poems of Ancient Relics," his helplessness with the current situation and alienation from the dynasty was expressed by traveling to Zhaojun's hometown and recalling Zhaojun's story. It is the multi-faceted image of Zhaojun that generates the everlasting Zhaojun culture. Xingshan County's publicity of Zhaojun's image focuses on "multiple angles" and "deep levels," and absorbs valuable resources of various poetry, operas and other literary works, unveiling the publicity highlight of showing Zhaojun's different personality charms from a literary perspective. While the second highlight lies in the emphasis on peace upholding through historical facts, making a new-era contribution to national peace from a political perspective. Finally, Zhaojun's courageous personality and great love for the country as a woman establishes herself as a model worthy of respect and study in today's society from the perspective of human nature.

\subsection{Based on Integrated Brands}

The brand building of characters revivifies the celebrity and culture in the history books, among which characteristic culture is the lifeline of the sustainable development of the brand. "Culture is the starting point and destination of tourism, the source of attraction of tourist landscape and the soul of tourism." (3) As the hometown of Zhaojun, Xingshan County boasts natural geographical and cultural advantages. Coupled with the multi-angle and multi-directional grasp of Zhaojun's image, three types of brands can be created. The first one is the integrated brand of Xingshan Zhaojun's hometown, mainly based on Zhaojun's living environment, such as special festivals including the Zhaojun Village Lantern Festival on August 15 and the chrysanthemum exhibition at the end of September. These festivals not only integrate regional characteristics but also encompass Zhaojun culture. Another way is through cultural influence, ranging from cultural relics exhibition at Zhaojun Memorial Hall to the musical performance of "Zhaojun Leaves Hometown." The second one is to integrate the brand with the local culture of Hohhot. Hohhot can be regarded as the place where Zhaojun has lived for the longest time. These two places, though far apart from each other, are connected by Zhaojun. The development of the "Zhaojun Marriage" cultural tourism route enables tourists to cross the historical river and approach the true story of Zhaojun. Such an economic corridor realizes cross-regional tourism and cultural integration, guaranteeing continuous economic development in these two places. The third one focuses on the integrated brand of Yichang and its surrounding culture, such as the hometown of navel oranges, the hometown of Quyuan. These are all synonymous with Yichang. Combining two or three products to be a new tourist route product will enrich the tourism options in Yichang. More cost-effective, of course, it will attract more tourists to choose Yichang. Establishing the Zhaojun brand cannot be achieved overnight, but requires continuous integration and innovation.

\section{COMBINE CULTURE AND INTANGIBLE HERITAGE TO PROMOTE INTANGIBLE HERITAGE INHERITANCE AND CONSOLIDATE A SOLID CULTURAL FOUNDATION}

Intangible cultural heritage has been the memory core and spiritual gene of the Chinese nation. Given its historical and national characteristics, it has been the focus of cultural development in various regions over the years. The trade-off between its protection and development has also been a difficult problem for the government's planning strategy. Building a brand with integration and inheritance has proved to be one of the effective ways to revivify intangible cultural heritage. It is an inevitable trend for Zhaojun culture, a national-level intangible cultural heritage, to integrate and develop with other intangible cultural heritages in Xingshan County. The legend of Wang Zhaojun, weeding gongs and drums, and Xingshan folk songs are 
one of the few national intangible cultural heritages in Xingshan County, the integrated development of which not only help expand the overall influence of intangible cultural heritage of Xingshan County, but also promotes the development in the local cultural tourism industry and social economy. To protect intangible cultural heritage and promote the development of intangible cultural heritage, Xingshan County has built a three-dimensional framework with Xingshan characteristics in light of "starting from inheritors and supplemented by learning and inheritance platforms."

\subsection{Stage Integration}

"Stage integration," that is, the space integration on the communication platforms, which can be divided into small spaces - "display platform" and large spaces "display attractions." "Guyin Hall," a space newly built-in Zhaojun Village to display intangible cultural heritage, is a representative of the small space. Through live performances, VR simulations, photo displays, and other methods, Xingshan's rich intangible cultural heritages are vividly presented. In contrast, larger spaces are embodied in Zhaojun Village attractions. While sightseeing, tourists can also learn about weeding gongs and drums and Xingshan folk songs, experience the cultural heritage of Xingshan, capture the characteristics of Xingshan's intangible cultural heritage, and promote the popularity of Xingshan intangible cultural heritage. It is also a good option to increase the singing popularity of intangible cultural heritage through celebrity attractiveness. For example, Li Yugang, a national first-level actor of the Opera, got inspiration from his visit to Chen Jiazhen, the inheritor of Xingshan folk songs, and then incorporated Xingshan folk songs into the stage play "Zhaojun Departs the Frontier," which received favorable responses.

\subsection{Tourism Integration}

"Tourism integration" represents the integration of communication activities. For example, co-organized festivals can not only enrich the activities and unveil the beauty of intangible cultural heritage, but also attract more tourists to boost the development of related industrial chains and increase local economic benefits. "2020 Hubei Zhaojun Cultural Tourism Festival", held in Zhaojun Town in Xingshan County, was an intangible cultural heritage activity including seven exciting programs like the Legend of Zhaojun, Xingshan Folk Songs, Xingshan Wei Drums and Xingshan Weeding Gongs and Drums. While the programs were welcomed and acclaimed by tourists worldwide, considerable income was earned by the intangible cultural inheritance performers, contributing to the rising economic development and rural revitalization innovation. Be it weeding gongs and drums, or Xingshan Caitang drama, tourists can see diversified intangible cultural heritage displays featuring the local characteristics. Among all these, the "Legend of Wang Zhaojun" covers the childhood and youth life of Zhaojun. When these stories are interpreted in local dialects, visitors from different places can always leave in their minds the unique imprint of Zhaojun and Xingshan.

\subsection{Community Integration}

"Community integration" refers to the integration of development thinking. Correct development thinking constitutes one of the secrets behind the successful operation. To consolidate the development foundation in Xingshan County to realize the revitalization of new villages and industries cannot be separated from the government's in-depth thinking innovation. Besides, the intangible heritage culture, carrying the cultural context of Xingshan County for thousands of years, has been integrated into the spirit of the local villagers. If Zhaojun culture is to keep pace with other intangible cultural heritage, the joint efforts of intangible cultural inheritors and local cultural centers are thus required to create a strong cultural atmosphere of intangible cultural inheritance.

It is far from enough for the Zhaojun culture communication to rely solely on the legend and image of Zhaojun. Only by developing with Xingshan intangible cultural heritages can a new height be reached for the development of Xingshan County through integration. Just as the publicity of Xingshan Cultural Center to "widely gather" and build a local intangible heritage "museum," intangible cultural inheritors are gathered, and a platform is built for everyone to be the "actors." Now, intangible cultural inheritors telling Zhaojun's story has established itself as a classic project in the intangible cultural heritage "museum," receiving wide acclamation.

\section{CONCLUSION}

Xingshan County, with the integration of Zhaojun culture, has turned to be a beautiful village in its true sense, not just limiting to the scenery. As the hometown of Zhaojun is inseparable from Zhaojun's growth, Zhaojun, to a large extent, symbolizes the image of Xingshan. Zhaojun's image charm and tortuous historical story have exerted valuable spiritual, economic and scientific value for the local area. The successful poverty alleviation and rapid development of Xingshan County have enlightened other places on rural revitalization that it is imperative to explore and trace regional historical resources as well as establish and promote unique cultural brands. And the building of a beautiful village calls for the practical promotion of its environment and culture with further inheritance and protection. 


\section{ACKNOWLEDGMENT}

Thanks for the support from the Federation of Social Sciences in Yichang and the 2021 Yichang Social Science Research Project (No. Ysk21kt094).

\section{REFERENCES}

[1] The Release of the $47^{\text {th }}$ Statistical Report on Internet Development in China $[\mathrm{J}]$. China Broadcasting, 2021 (04).
[2] Wu LC, Xie SL. Rural Cultural Revitalization from the Perspective of Cultural Governance: Value Coupling and System Construction[J]. Journal of Huazhong Agricultural University (Social Science Edition), 2019(01).

[3] Jiang Changbao. Promoting Effect of Tourism Culture on Regional Economic Development[J]. Guizhou Social Sciences, 2004(5). 